\title{
Genetic and morphological population differentiation in the rock-dwelling and specialized shrimp-feeding cichlid fish species Altolamprologus compressiceps from Lake Tanganyika, East Africa
}

\author{
Maria Luise Spreitzer · Selma Mautner • \\ Lawrence Makasa $\cdot$ Christian Sturmbauer
}

Received: 28 July 2010/Accepted: 3 April 2011/Published online: 1 June 2011

(C) The Author(s) 2011. This article is published with open access at Springerlink.com

\begin{abstract}
With about 250 endemic species, Lake Tanganyika contains an extraordinarily diverse cichlid fish fauna, and thus represents an ideal model system for the study of pathways and processes of speciation. The Lamprologini form the most speciesrich tribe in Lake Tanganyika comprising about 100 species in seven genera, most of which are endemic to the lake. They are territorial substrate-breeders and represent a monophyletic tribe. By combined analysis of population genetics and geometric morphometric markers, we assessed gene flow among three populations of the highly specialized shrimp-feeding rockdweller Altolamprologus compressiceps, separated by geographic distance and ecological barriers. Five
\end{abstract}

Electronic supplementary material The online version of this article (doi:10.1007/s10750-011-0698-0) contains supplementary material, which is available to authorized users.

Guest editors: C. Sturmbauer, C. Albrecht, S. Trajanovski \& T. Wilke / Evolution and Biodiversity in Ancient Lakes

M. L. Spreitzer · S. Mautner · C. Sturmbauer $(\bowtie)$

Department of Zoology, University of Graz,

Universitätsplatz 2, 8010 Graz, Austria

e-mail: christian.sturmbauer@uni-graz.at

L. Makasa

Department of Fisheries, Mpulungu, Zambia

Present Address:

M. L. Spreitzer

Department of Biology, University of Konstanz,

Universitätsstraße 10, 78457 Constance, Germany highly polymorphic microsatellite markers were analyzed in conjunction with 17 landmarks in order to compare genetic differences to body shape differences among populations. Both genetic and morphological analyses revealed significant differentiation among the three studied populations. A significant, but overall relatively low degree of genetic differentiation supports a very recent divergence. Phenotypic differentiation was primarily found in the head region of A. compressiceps. In agreement with findings in other cichlid species, similar adaptations to specialized feeding mechanisms can consequently lead to marginal shape changes in the trophic apparatus.

Keywords Lamprologini - Geometric morphometrics $\cdot$ Microsatellites $\cdot$ Population differentiation $\cdot$ Speciation $\cdot$ Zambia

\section{Introduction}

With their unique species assemblages, the Great Lakes of East Africa represent ideal model systems to study evolutionary processes. Lake Tanganyika is the oldest of the three East African Great Lakes with an estimated age of 9-12 myr (Cohen et al., 1993) and considered to be one of the most diverse freshwater ecosystems in the world. It is well known for its outstandingly diverse cichlid fish fauna that is characterized by an extraordinary high degree of endemism (Fryer \& Iles, 1972). The species flock is 
older and the degree of ecological and morphological divergence among species is more extreme than in the other two Great Lakes (Greenwood, 1984). Many species show a high degree of population differentiation in terms of color and genetics along the shoreline (Sturmbauer \& Meyer, 1992; Duftner et al., 2006; Sefc et al., 2007; Koblmüller et al., 2009). Thus, Lake Tanganyika is an ideal ecosystem to study genetic and phenotypic divergence and the formation of locally differentiated populations along its shoreline which in some parts is highly structured into rocky and sandy stretches. This is especially true for species that are restricted to a special type of habitat which is distributed discontinuously along the lake shores (Sturmbauer \& Meyer, 1992; Kornfield \& Smith, 2000; Duftner et al., 2006; Sefc et al., 2007).

The tribe Lamprologini is the most species-rich tribe of Lake Tanganyika comprising about 90 species in seven genera (Poll, 1956, 1986; Colombe \& Allgayer, 1985; Stiassny, 1991; Schelly et al., 2006; Koblmüller et al., 2007; Day et al., 2007). This substrate-spawning lineage is monophyletic in Poll's classification (Poll, 1986) and contains both endemic and non-endemic species (Sturmbauer et al., 1994). Non-endemic species have, besides inhabiting Lake Tanganyika itself, also colonized the Zaire River system (Sturmbauer et al., 1994) and the Malagarazi River (De Vos \& Seegers, 1998). Outstanding diversity in morphology, behavior, and ecology makes members of this tribe particularly interesting when studying pathways of adaptive radiation (Sturmbauer et al., 1994). The genus Altolamprologus comprises two described species, Altolamprologus compressiceps and Altolamprologus calvus (Boulenger 1898), and possibly at least one gastropod shell breeding dwarf species (Konings, 1998). A. compressiceps is distributed all over the entire lake and lives in sympatry with A. calvus at the south-western part of the lake (Konings, 1998).

A mitochondrial phylogeny of the genus Altolamprologus showed that both described species are of quite recent origin and started to spread and diverge into color morphs very recently (Ernst, 2008). Furthermore, A. calvus is considered not to be completely genetically separated from A. compressiceps in the mtDNA phylogeny, in that lineage sorting toward populations of A. calvus is incomplete (Ernst, 2008). As the two entities are stable despite of sympatry, one can assume complete reproductive isolation. However, current data do not allow us to be certain that no genes are exchanged at very low frequency. A. compressiceps and A. calvus have a highly specialized morphology (Brichard, 1999), characterized by a very slender and high body and a tapered mouth. Jaws can be protruded for suction feeding and its teeth are forceps-like. In addition, eyes can be turned $90^{\circ}$ out of their usual position. The genus Altolamprologus feeds specifically on shrimp of the family Atyidae (Yuma, 1994) and it thus seems highly likely that the peculiarly depressed body is a particular adaptation to this mode of foraging, since a laterally depressed body allows easier access to narrow rock crevices. Both species are restricted to rock- or cobble habitats, and in some cases gastropod shell beds.

It has been argued that distinct trophic adaptation and the strong bond to a specific type of habitat can facilitate population differentiation across ecological barriers and eventually lead to speciation (Sturmbauer, 1998). A. compressiceps is such a stenotopic and strongly habitat-bound species and thus is expected to exhibit a relatively high degree of differentiation among populations. Indeed, several color variants were found across the entire lake (Konings, 1998). Given its relatively young evolutionary age, a rather rapid local divergence is likely to have happened in this species.

As population structure can result in restricted gene flow, color variation and local adaptation in particular morphological features that indicate a rapid population divergence, population studies need to address both genetic and phenotypic divergence. Geometric morphometrics, a landmark-based approach for investigating body shape changes, has been shown to be able to detect fine-scale morphological differences in overall body shape. Furthermore, this technique has the potential to discriminate among assemblages with recent common ancestry (Adams et al., 2004; Maderbacher et al., 2008). Even populations living in only marginally different environmental conditions can exhibit morphological differences which can be detected by geometric morphometrics. In combination with neutral genetic markers, changes in the phenotype of an organism can be used to assess the intensity and direction of natural selection (Raeymaekers et al., 2007).

This study investigates to which extent morphological and genetic differentiation occurred among three 
geographically separated populations of the highly specialized shrimp-feeding rock-dweller A. compressiceps in the South of Lake Tanganyika.

\section{Materials and methods}

Sampling

119 individuals of A. compressiceps (54 males, 46 females, 20 unknown) were sampled from three different sites at the southern tip of Lake Tanganyika in Zambia (Mwese $n=39,\left[08^{\circ} 34^{\prime} \mathrm{S}, 30^{\circ} 47^{\prime} \mathrm{E}\right.$ ], Kasakalawe $n=40 \quad\left[08^{\circ} 47^{\prime} \mathrm{S}, 31^{\circ} 04^{\prime} \mathrm{E}\right]$, Wonzye $n=40 \quad\left[08^{\circ} 43^{\prime} \mathrm{S}, 31^{\circ} 08^{\prime} \mathrm{E}\right]$, see Fig. 1). Fin clips were taken from all individuals and preserved in $99 \%$ ethanol for DNA extraction. Whole specimens were stored in $10 \%$ formalin for geometric morphometric analysis.

DNA extraction and microsatellite amplification

Whole genomic DNA was extracted from 119 specimens using a high-salt, ammonium acetate extraction protocol after a proteinase $\mathrm{K}$ digestion (modified after Bruford et al., 1998). Eleven polymorphic microsatellite loci developed for other cichlid species were screened for use in A. compressiceps. Five loci gave consistent results and exhibited enough variation to be used for population genetic analyses. Microsatellites were PCR-amplified in a 10 or $20 \mu \mathrm{l}$ reaction mix containing $5-10 \mathrm{ng}$ extracted DNA, $0.25 \mathrm{pM}$ of each primer, $0.05 \mathrm{mM}$ dNTP mix, $10 \mu \mathrm{g} / \mu \mathrm{l}$ BSA, $1.5 \mathrm{mM} \mathrm{MgCl}_{2}, 10 \times$ Taq polymerase buffer and $0.5 \mathrm{U}$ Taq DNA Polymerase. Forward primers were labeled with three different fluorescent dyes FAM, HEX, and NED. The PCR protocol started with an initial denaturation step at $94^{\circ} \mathrm{C}$ for $3 \mathrm{~min}$ followed by 40 cycles at $94^{\circ} \mathrm{C}$ for $30 \mathrm{~s}$, annealing at $50-54^{\circ} \mathrm{C}$ for $30 \mathrm{~s}$ (specific annealing temperatures see Table 1) and extension at $72^{\circ} \mathrm{C}$ for $1 \mathrm{~min}$ followed by a final extension at $72^{\circ} \mathrm{C}$ for 7 min. PCR products were analyzed on an $\mathrm{ABI}$ 3130xl sequencer together with an ABI ROX500 size standard and allele calling was performed with GeneMapper software version 3.7.

\section{Data analysis}

To detect scoring errors and genotyping artifacts such as null alleles, large allele dropout and stutter bands we used MICRO-CHECKER (van Oosterhout et al., 2004). Parameters of genetic diversity as number of alleles $\left(N_{\mathrm{A}}\right)$, observed $\left(H_{\mathrm{O}}\right)$ and expected $\left(H_{\mathrm{E}}\right)$ heterozygosity and departures from Hardy-Weinberg equilibrium were calculated in Arlequin ver.3.11 (Excoffier et al., 2005). Arlequin was also used to quantify pairwise population differentiation calculating FST based on allele frequencies (assuming the infinite allele model IAM, Weir \& Cockerham, 1984) and RST based on allele sizes assuming the stepwise mutation model (SMM, Slatkin, 1995). We also
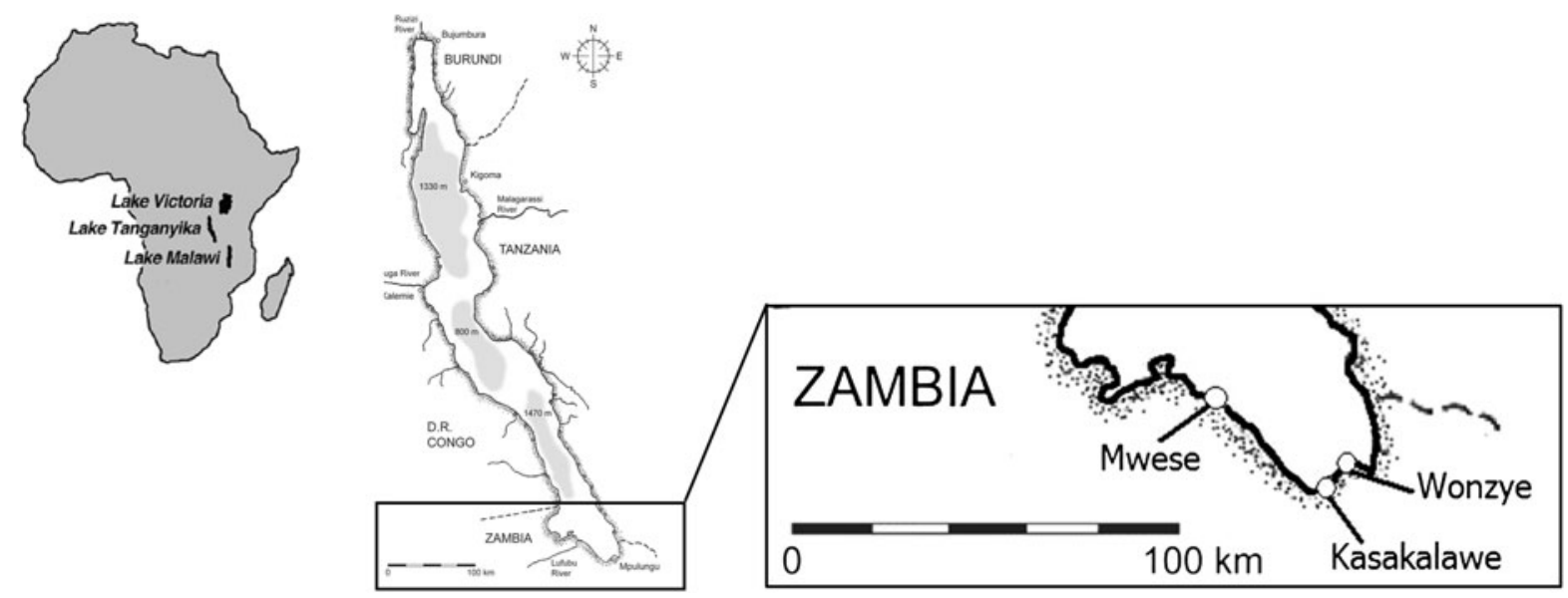

Fig. 1 Geographical location of Lake Tanganyika in East Africa, map of Lake Tanganyika with details of southern shore including sampling locations (Mwese, Kasakalawe and Wonzye) 
Table 1 Characterization of five microsatellite loci: size range, number of alleles $\left(N_{\mathrm{A}}\right)$, observed $\left(H_{\mathrm{O}}\right)$ and expected $\left(H_{\mathrm{E}}\right)$ heterozygosity and species in which the microsatellite locus was developed

\begin{tabular}{llllllll}
\hline Locus & Size range $(\mathrm{bp})$ & $T_{\mathrm{a}}\left({ }^{\circ} \mathrm{C}\right)$ & $N_{\mathrm{A}}$ & $H_{\mathrm{O}}$ & $H_{\mathrm{E}}$ & Species & Citation \\
\hline Pmv17 & $122-232$ & 52 & 28 & 0.95 & 0.93 & Pseudocrenilabrus multicolor victoriae & Crispo et al. (2007) \\
Pmv3 & $101-163$ & 50 & 15 & 0.76 & 0.77 & Pseudocrenilabrus multicolor victoriae & Crispo et al. (2007) \\
UNH952 & $133-177$ & 54 & 18 & 0.87 & 0.78 & Oreochromis niloticus & Carleton et al. (2002) \\
Pzeb1 & $105-139$ & 54 & 11 & 0.77 & 0.62 & Pseudotropheus zebra & Van Oppen et al. (1997) \\
TmoM11 & $146-200$ & 54 & 22 & 0.87 & 0.86 & Tropheus moorii & Zardoya et al. (1996) \\
\hline
\end{tabular}

tested for isolation-by-distance performing a Mantel test.

Factorial correspondence analysis (FCA), a multivariable analysis to visualize genetic distances between genotypes, was performed in GENETIX ver.4.05.2 using the AFC3D procedure (Belkhir et al., 1996-2004). Factorial axes are ordered according to their eigenvalues, larger values explaining more of the general structure in the dataset. Using the software STRUCTURE version 2.2 (Pritchard et al., 2000), we conducted a population assignment test using Bayesian clustering based on allele frequencies to calculate the most probable number of populations $(k)$ and to assign individuals to their population of origin. For each $k$ (ranging form $k=1$ to $k=3$ ) we computed three iterations with a burn-in of 100,000 and 100,000 MCMC replicates using the admixture model (ancestry model) which assumes some degree of gene flow so that it may be possible that specimens stem from more than a single population. Furthermore, we chose the model of correlated allele frequencies which implies that all populations once originated from a single ancestral population and that observed genetic divergence is the result of genetic drift accumulating since the divergence (Martien et al., 2007). In addition, a recently implemented model for populations with low genetic divergence was used (Hubisz et al., 2009). For each value of $k$, we selected the MCMC run with the lowest estimated posterior probability ( $\mathrm{Ln} \mathrm{P}(\mathrm{D})$ ).

To investigate the historical population demography (population expansion), meta-population analyses were conducted. This was performed using the software BOTTLENECK ver.1.2.02 (Cornuet \& Luikard, 1996) for detecting recent bottleneck events on the basis of allele frequency data. Populations that recently experienced a dramatic decline in effective population size are characterized by a significant excess in heterozygotes. We performed a Wilcoxon sign rank test to calculate probabilities for heterozygote excess in all three populations for three mutation models (IAM, TPM and SMM). To estimate population sizes and past migration rates among the three studied populations, we used MIGRATE ver.3.0.3 (Beerli \& Felsenstein, 1999, 2001) applying a maximum likelihood inference. We used the stepwise mutation model for microsatellite markers and applied a MCMC approach, where we calculated 10 short chains (500 used trees out of sampled 10,000) and 3 long chains $(5,000$ used trees out of sampled 100,000). A migration matrix model with unequal population sizes and different migration rates was assumed (Beerli \& Felsenstein, 1999, 2001).

Geometric morphometrics

113 specimens of $A$. compressiceps, which were also used for genetic analysis, were subjected to geometric morphometric analysis. The left body side of each preserved fish was scanned with a flatbed-scanner (Herler et al., 2007). On the basis of the landmark system introduced by Maderbacher et al. (2008) we developed a set of 17 homologous landmarks for A. compressiceps. Those landmarks were digitized for each specimen (Fig. 2) using tpsDIG (SUNY at Stony Brook, Rohlf 2003) to obtain coordinates for all 17 landmarks in all 113 specimens. Analysis of landmark data was carried out with IMP software (Sheets, 2003). Procrustes analysis was implemented to obtain shape information that is independent from position (orientation and rotation), size and location. For this study, partial procrustes superimposition was performed in CoordGen6f (IMP package, Sheets, 2003).

To evaluate the degree of variation among the three studied populations, a principal component analysis (PCA) was carried out in PCAGen6n (IMP package, Sheets, 2003) which creates a set of new 


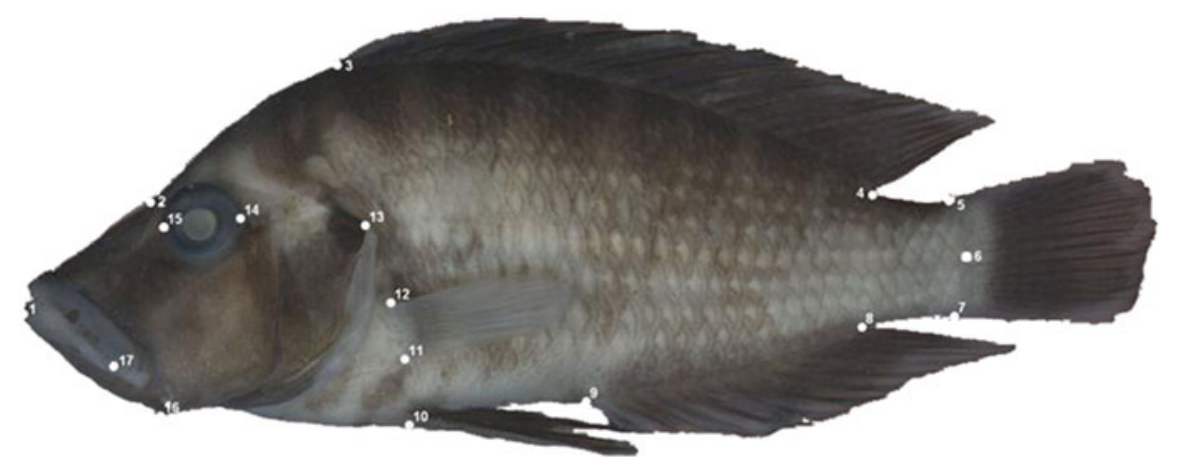

Fig. 2 Landmark positions for geometric morphometric analysis. (1) Anterior tip of snout (2) groove at basis of forehead (3, 4 ) anterior and posterior insertion of dorsal fin $(5,7)$ upper and lower insertion of caudal fin (6) midpoint of origin of caudal fin $(8,9)$ posterior and anterior insertion of anal fin $(10)$ insertion

independent variables that best describe the variance among studied populations. To study the overlap among populations a Canonical Variate Analysis (CVA) was carried out in CVAGen6j (IMP package, Sheets, 2003), that calculates partial warp scores to perform a CVA after a MANOVA (multivariate analysis of variance). Principal components maximize the variance of individual scores whereas canonical variates maximize the variance between the group means relative to the variance within the groups, thus leading to an optimal linear discrimination between the groups. For pairwise population comparison, deformation grids as well as Goodall's $F$-test were calculated in TwoGroup6h (IMP package, Sheets, 2003).

\section{Results}

Genetic population differentiation

A total of 94 alleles were detected in five microsatellite loci. All five loci were highly polymorphic and all three populations displayed a high degree of genetic diversity (Mwese 0.780; Kasakalawe 0.783; Wonzye 0.820). Numbers of alleles per locus ranged from 11 (Pzeb1) to 28 (Pmv17) and populations were characterized by a total numbers of alleles as follows, 64 (Mwese), 66 (Kasakalawe), and 66 (Wonzye). A detailed characterization of all five loci (size range, number of alleles, observed and expected heterozygosity per locus) is given in Table 1. Parameters of genetic diversity in the three studied populations of ventral fin $(11,12)$ lower and upper insertion of pelvic fin (13) most posterior point of operculum $(14,15)$ extreme of orbit along the anteroposterior body axis (16) most posterior point of chin (17) most posterior point of mouth cleavage

(number of alleles, observed and expected heterozygosity per locus and population) can be found in Table 2. One locus, Pzeb1, showed significant

Table 2 Parameters of genetic diversity in three populations

\begin{tabular}{|c|c|c|c|}
\hline & $\begin{array}{l}\text { Mwese } \\
n=39\end{array}$ & $\begin{array}{l}\text { Kasakalawe } \\
n=40\end{array}$ & $\begin{array}{l}\text { Wonzye } \\
n=40\end{array}$ \\
\hline \multicolumn{4}{|c|}{ Pmv17 (122-232 bp) } \\
\hline$N_{\mathrm{A}}$ & 21 & 21 & 24 \\
\hline $\mathrm{H}_{\mathrm{O}}$ & 0.97 & 0.90 & 0.98 \\
\hline $\mathrm{H}_{\mathrm{E}}$ & 0.95 & 0.89 & 0.95 \\
\hline \multicolumn{4}{|c|}{ Pmv3 (101-163 bp) } \\
\hline$N_{\mathrm{A}}$ & 9 & 9 & 9 \\
\hline $\mathrm{H}_{\mathrm{O}}$ & 0.67 & 0.90 & $0.73 * *$ \\
\hline $\mathrm{H}_{\mathrm{E}}$ & 0.74 & 0.79 & 0.78 \\
\hline \multicolumn{4}{|c|}{ UNH952 (133-177 bp) } \\
\hline$N_{\mathrm{A}}$ & 11 & 14 & 13 \\
\hline $\mathrm{H}_{\mathrm{O}}$ & 0.92 & 0.93 & 0.75 \\
\hline $\mathrm{H}_{\mathrm{E}}$ & 0.82 & 0.82 & 0.71 \\
\hline \multicolumn{4}{|c|}{ Pzeb1 (105-139 bp) } \\
\hline$N_{\mathrm{A}}$ & 6 & 8 & 5 \\
\hline $\mathrm{H}_{\mathrm{O}}$ & $0.74 * *$ & $0.65^{*}$ & $0.91 * * *$ \\
\hline $\mathrm{H}_{\mathrm{E}}$ & 0.62 & 0.58 & 0.67 \\
\hline \multicolumn{4}{|c|}{ TmoM11 (146-200 bp) } \\
\hline$N_{\mathrm{A}}$ & 17 & 14 & 15 \\
\hline $\mathrm{H}_{\mathrm{O}}$ & 0.92 & 0.98 & 0.70 \\
\hline $\mathrm{H}_{\mathrm{E}}$ & 0.90 & 0.84 & 0.84 \\
\hline
\end{tabular}

Number of alleles $\left(N_{\mathrm{A}}\right)$, observed $\left(\mathrm{H}_{\mathrm{O}}\right)$, and expected $\left(\mathrm{H}_{\mathrm{E}}\right)$ heterozygosity per locus and population. Asterisks show significant deviations from Hardy-Weinberg equilibrium. Significance levels $* P<0.05$, ** $P<0.01$, and $* * * P<$ 0.001 
deviation from Hardy-Weinberg equilibrium in all three populations exhibiting an excess of heterozygotes. No evidence of null alleles or scoring errors was detected in Pzeb1 or any other locus. After excluding Pzeb1 from further analyses, $F_{\mathrm{ST}}$ values still remained highly significant $(P<0.001)$.

Factorial correspondence analysis of microsatellite data showed a tendency of population separation with some individuals overlapping (Fig. 3). The first three factorial axes explain $11 \%$ of the total genetic variance. Eigenvalues of the axes are 0.34, 0.31, and 0.30. Wonzye was separated from Mwese through factorial component 1 (3.8\%) whereas Kasakalawe was separated from Wonzye and Mwese through factorial component $2(3.5 \%)$.

Pairwise population differentiation between all three populations based on allele frequencies $\left(F_{\mathrm{ST}}\right)$ showed relatively low values $(0.017-0.027)$ but all were highly significant (Table 3). Population differentiation based on allele sizes $\left(R_{\mathrm{ST}}\right)$ also exhibited rather low values (0.006-0.028) with two population comparisons showing significant differentiation (Mwese-Wonzye and Kasakalawe-Wonzye). Population comparison between Mwese and Kasakalawe could not address significant differentiation (Table 3). Genetic differentiation was highest between Kasakalawe and Wonzye despite the smallest geographical distance. Therefore, a Mantel test did not show any significant correlations between geographic and genetic distances among populations that indicates no isolation by distance. Population assignment tests using a Bayesian clustering method based on allele frequencies conducted with STRUCTURE could not infer the right number of populations and were not able to assign individuals to their population of origin. Even using a new, recently implemented model in STRUCTURE which compensates low levels of genetic divergence (Hubisz et al., 2009), no population structure was detected most likely due to very low $F_{\mathrm{ST}}$ values obtained from pairwise population comparisons.

No recent genetic bottleneck was inferred by BOTTLENECK as no significant heterozygosity excess was detected except for Mwese under the infinite allele model. Estimations of population sizes and past migration rates among the three studied populations performed in MIGRATE (Beerli \& Felsenstein, 1999, 2001) showed that Theta, describing population sizes, ranged from 7.11 (Mwese) to 10.65 (Wonzye). Migration rates $(M)$ were almost the

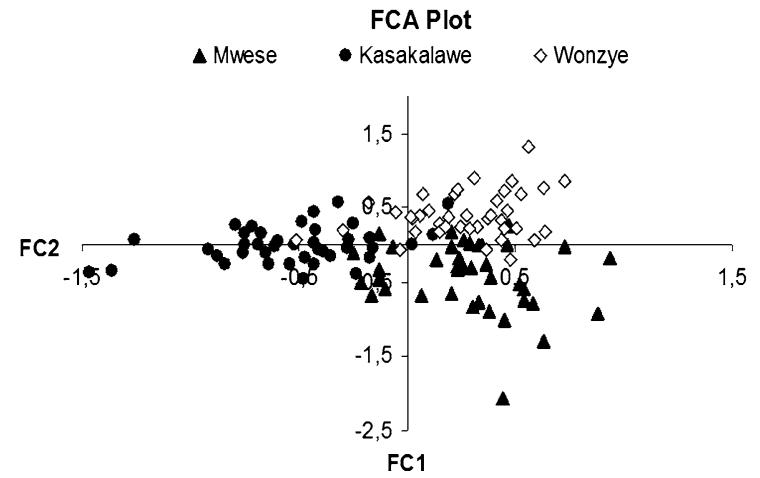

Fig. 3 Results of the factorial correspondence analysis (FCA) of microsatellite data

Table 3 Pairwise population differentiation among three populations: $F_{\mathrm{ST}} / R_{\mathrm{ST}}$ values below diagonal, Goodall's $F$ values above diagonal

\begin{tabular}{llll}
\hline & Mwese & Kasakalawe & Wonzye \\
\hline Mwese & - & $* * * 33.24$ & $* * * 7.7$ \\
Kasakalawe & $* * * 0.017 / 0.006$ & - & $* * * 7.43$ \\
Wonzye & $* * * 0.019 / * 0.025$ & $* * * 0.027 / * 0.028$ & - \\
\hline
\end{tabular}

Significance levels of $P<0.05, P<0.01, P<0.001$ are indicated as $* * *$, and $* * *$

same among all populations but Mwese showed slightly higher immigration rates than Kasakalawe and Wonzye (Table 4). Immigration rates from Kasakalawe and Wonzye to Mwese were 2.0 and 1.9 individuals per generation, respectively.

Geometric morphometrics

Principal component analysis (PCA) could not clearly separate distinct clusters of populations but nevertheless showed a tendency of population differentiation (Fig. 4). Specimens from Mwese and Kasakalawe were partly overlapping on Principal Component 2 (describing $9.8 \%$ of total variance). Specimens from Wonzye completely overlapped with the other two populations. Principal Component 1 described $65.5 \%$ of total variance but along this axis there is no population separation observable.

Canonical variate analysis (CVA) of 17 landmarks showed a stronger tendency of population separation because of a better linear discrimination of groups (Fig. 5). Some individuals were overlapping which was observed more frequently between specimens from Mwese and Wonzye than between other 
Table 4 Results of the migration rate analysis: Pairwise population comparisons of population sizes (Theta) and migration rates $(M)$ among the three studied populations

\begin{tabular}{lllll}
\hline Population & Theta $[\times \mathrm{Ne} \mathrm{mu}]$ & \multicolumn{3}{l}{$M(\mathrm{~m} / \mathrm{mu})[+=$ receiving population $]$} \\
\cline { 3 - 5 } & & $1,+$ & $2,+$ & 2.002 \\
Mwese & 7.11 & - & - & 1.990 \\
Kasakalawe & 8.32 & 1.189 & 1.628 & - \\
Wonzye & 10.65 & 1.881 & -098 \\
\hline
\end{tabular}

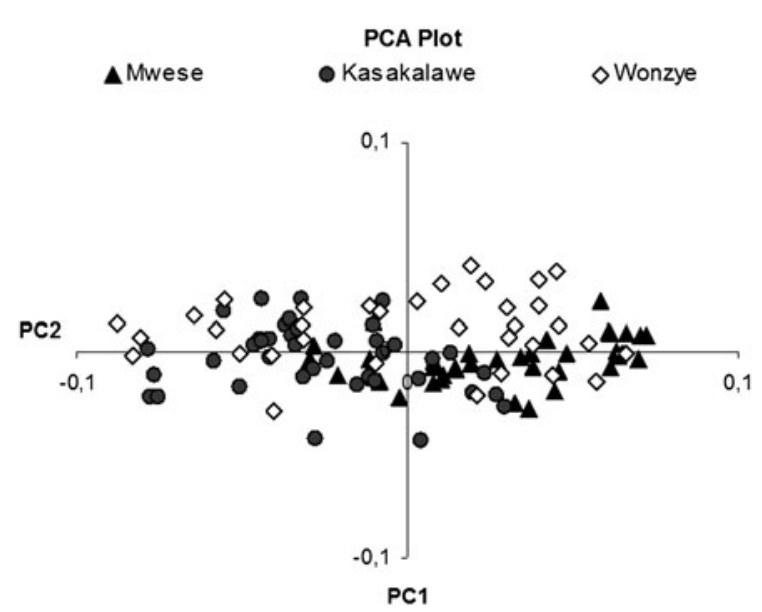

Fig. 4 Results of the principal component analysis (PCA)

populations. Mwese was separated from Wonzye through Canonical Variate 1 (Eigenvalue 2.1196) whereas Kasakalawe showed separation from Mwese and Wonzye through Canonical Variate 2 (Eigenvalue 1.0361). Pairwise population differentiation based on shape change (Goodall's $F$ test) showed highly significant results. Highest morphological differentiation was found between Mwese and Kasakalawe, whereas $F_{\mathrm{ST}}$ scores obtained from comparisons between Mwese-Wonzye and Kasakalawe-Wonzye were very similar (Table 3). Deformation grids showing pairwise population comparisons indicate that shape changes mainly occurred in the head region of A. compressiceps in all three population comparisons (Fig. $6 \mathrm{a}-\mathrm{c}$ ).

\section{Discussion}

Genetic population differentiation

Species exhibiting intraspecific variation provide ideal opportunities to study evolutionary processes responsible for diversification. Natural selection, sexual

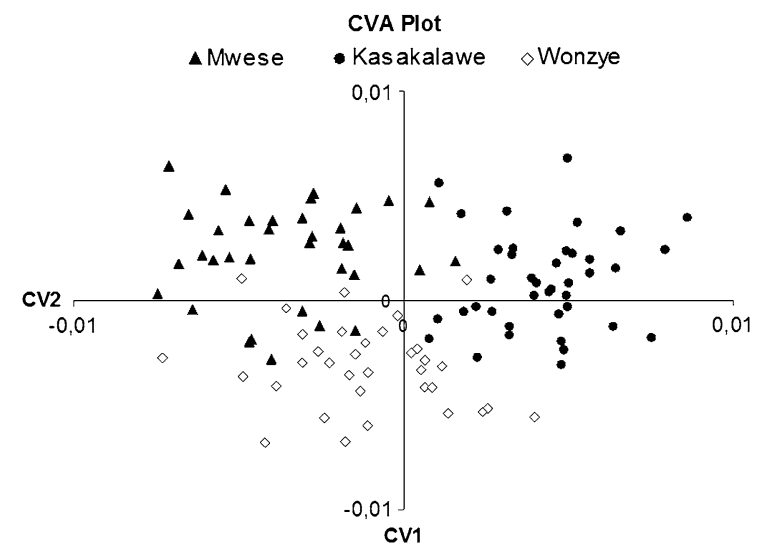

Fig. 5 Results of the canonical variate analysis (CVA) of 17 landmarks

selection, genetic drift, or a combination of these factors, may act as diversifying forces. In this respect, coloration has received much attention as it responds to natural and sexual selection (Endler, 1983; Seehausen \& van Alphen, 1999), but may also evolve through drift alone (Hoffman et al., 2006). Moreover, speciesspecific characteristics like site fidelity, stenotopy through specialization to particular trophic niches, and territorial organization strongly influence the degree of genetic differentiation among local populations.

Pairwise population differentiation between all three populations based on allele frequencies $\left(F_{\mathrm{ST}}\right)$ showed relatively low values (1.75-2.74) but all were highly significant (Table 3). However, the observed values are well within the range among populations of other cichlid species in Lake Tanganyika. Variabilichromis moorii, a stenotopic herbivorous habitat specialist confined to rocky habitat without obvious morphological differentiation among sites showed at least twice as much genetic differentiation than A. compressiceps (genetic divergence ranging from 4.0-16.0\%, Duftner et al., 2006). Tropheus moorii, a highly phylopatric species of which about 120 color 
(a)

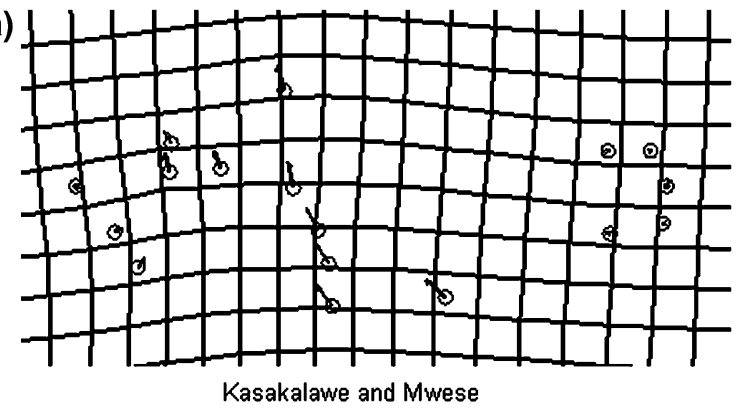

(c)

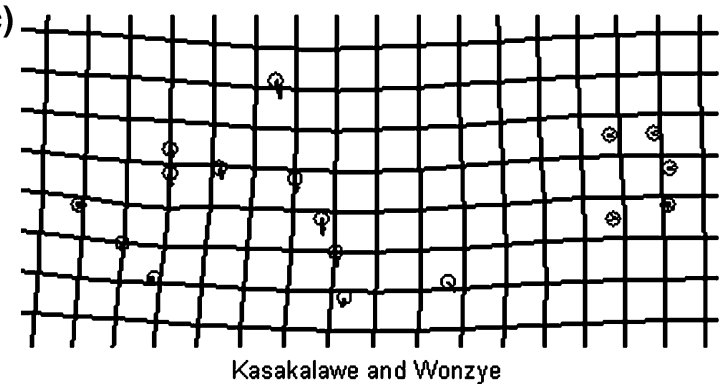

(b)

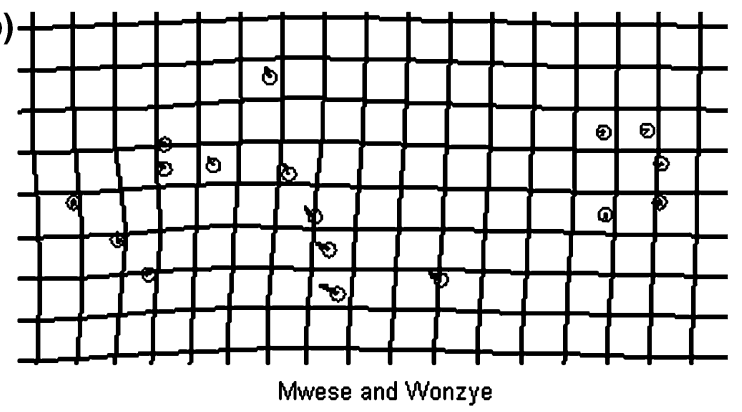

Fig. 6 Deformation grids: a Kasakalawe and Mwese, b Mwese and Wonzye, and c Kasakalawe and Wonzye. Arrow size and direction refer to the amount of divergence and the trend of morphological differentiation between the two compared populations

morphs are described (Konings, 1998; Schupke, 2003), showed a higher degree of genetic population divergence than $A$. compressiceps with $F_{\text {ST }}$ values of 3.1 to $6.8 \%$ (Sefc et al., 2007). Higher values of population differentiation $\left(F_{\mathrm{ST}}\right.$ ranging from 4.7-18.8\%) were found in Eretmodus cyanostictus, a species exhibiting a high degree of site philopatry (Sefc et al., 2007) but hardly any color differentiation. Moreover, the less highly philopatric and more mobile cichlid fish species Ophthalmotilapia ventralis ( $\mathrm{F}_{\mathrm{ST}}$ 0.9-1.4\%; Sefc et al., 2007) exhibited less genetic differentiation among populations than A. compressiceps. With a level of 1.8 to $2.7 \%$ of population differentiation $A$. compressiceps lies well above the values for more mobile species but remains in the lower range of more philopatric species. However, ongoing gene flow among populations might also explain rather low $F_{\mathrm{ST}}$ values in a stenotopic species like A. compressiceps (see also Martien et al., 2007).

$R_{\mathrm{ST}}$ values were generally lower than $F_{\mathrm{ST}}$ values, with two population comparisons showing significant results. As the stepwise mutation model represents a rather strict mutation model, such low values are not surprising given the overall low population differentiation among the three studied populations.
Despite its description as a habitat-bound species, analysis of past migration rates showed ongoing migration among all three studied populations even across larger geographic distances that could prevent more pronounced genetic differentiation. As little as one individual per generation can be sufficient to prevent substantial population differentiation (Wright, 1931). Taken together, the clear but low degree of population differentiation observed in $A$. compressiceps can best be explained by (1) its young evolutionary age and consequently recent spread along the southern shores of Lake Tanganyika and (2) by its rather stenotopic and habitat-bound life style. The question about the actual degree of ongoing gene flow among populations cannot be answered, but the existence of several color morphs which are either following the distribution of continuous rocky shore lines or rocky outcrops suggests very low levels of gene flow across habitat breakpoints. Such breakpoints are sandy stretches along the shoreline or river estuaries. They have been shown to promote population differentiation by preventing gene flow in species adapted to rocky habitats (Sefc et al., 2007).

As already mentioned, low levels of population differentiation over large geographic distances 
compared to other cichlids with similar life history traits indicates a relatively recent separation of $A$. compressiceps populations in the southern basin of Lake Tanganyika. This assumption is in accordance with results of a mitochondrial phylogeny suggesting a recent divergence of the genus Altolamprologus (Ernst, 2008) based on low levels of sequence divergence, frequently shared haplotypes and incomplete lineage sorting among A. compressiceps and A. calvus. According to a TCS haplotype network, Altolamprologus seems to have evolved from a local ancestor that underwent a second diversification. A. calvus seems to have split from a local $A$. compressiceps population, presumably somewhere in the southwest of the lake, and remained distributed quite locally. Based on mtDNA data, A. compressiceps and $A$. calvus are considered two closely related species. MtDNA data also showed that A. compressiceps first evolved in an unknown locality and subsequently dispersed across the entire lake (Ernst, 2008). Populations separated by large geographic distances (e.g., coast to coast) are expected to exhibit a higher level of genetic differentiation than adjacent populations. Even a large geographic distance between two populations in this study (about $40 \mathrm{~km}$ between Mwese and Wonzye) did not result in higher population differentiation than within smaller geographic ranges in A. compressiceps populations. This may possibly be due to the relative recent separation of the existing populations from a single ancestral population (Slatkin, 1993). Non-significant isolation by distance based on our microsatellite data might also be attributed to sampling at only three sites and using too few microsatellite loci. Even with an excess of heterozygotes at one locus, no bottleneck events were detected in any of the three populations.

This observation is interesting as significant demographic effects of the most recent water level fluctuations in Lake Tanganyika (32-14.000 years ago, Lezzar et al., 1996; Cohen et al., 1993, 1997; McGlue et al., 2008) have been suggested to be the major factor for observed demographic structure in other sympatric cichlid species (Verheyen et al., 1996; Sturmbauer et al., 2001). It may well be that the spread of Altolamprologus was too recent to show the same patterns as in species with pre-existing populations.
Morphological population differentiation

For the study of subtle morphological differences in overall body shape, landmark-based morphometric approaches are better able to visualize and quantify changes among populations than traditional methods (Adams et al., 2004; Maderbacher et al., 2008). In contrast to the nuclear genetic results (highest genetic differentiation between Kasakalawe and Wonzye), geometric morphometric analysis revealed highest phenotypic differentiation between Kasakalawe and Mwese (Goodall's $F$ of 33.24) which are separated by a geographical distance of about $40 \mathrm{~km}$ (Fig. 1). The deformation grid comparing these two populations (Fig. 6a) indicated that differences in morphology mostly occur in the head region. As head morphology was shown to be a strong indicator for trophic specialization, slight habitat differences may enforce slightly differential selection directions to promote local adaptation. If gene flow continues to be restricted, these adaptations concerning feeding efficiency could subsequently lead to greater differences in the trophic apparatus and might promote speciation. As A. calvus lives in sympatry in a relatively short stretch of coast line, its origin might have followed this scenario.

Maderbacher et al. (2008) studied the overall morphology of $T$. moorii applying traditional and geometric morphometrics, where the latter revealed significant differentiation among populations in body shape. Shape changes primarily occurred in the head region which is considered to be the most variable part in the cichlid body due to trophic specializations (Fryer \& Iles, 1972). As previous studies showed (e.g., Albertson \& Kocher, 2001; Albertson et al., 2003; Postl et al., 2008), the oral jaw apparatus plays a fundamental role in cichlid evolution and diversification. Postl et al. (2008) assessed the same populations of T. moorii as Maderbacher et al. (2008) using geometric morphometric methods investigating viscerocranial bone elements of the oral jaw apparatus. Results showed that most of these structures were highly conserved and did not show significant variation among populations, but the dentary, the tooth-bearing anterior part of the lower jaw, showed significant differentiation among studied populations. A. compressiceps, a feeding specialist for shrimp shows highly specialized morphological 
adaptations in the head region, a protrudable mouth for efficient suction feeding, as well as in overall body shape in the form of a highly compressed body (Yuma, 1994). More detailed studies investigating the oral jaw apparatus in A. compressiceps would be necessary to determine the degree of differentiation in these bony elements.

Despite the relatively young divergence in the genus Altolamprologus, significant population differentiation on a small geographic scale was found in nuclear DNA as well as overall morphology of $A$. compressiceps. Assuming an only recent dispersal across the southern lake basin based on mtDNA data, significant population differentiation may be due to special habitat and diet requirements, as well as restricted gene flow across ecological barriers. Although both genetic and morphological markers showed statistically significant population differentiation, levels of differentiation among populations are not consistent between markers. Overall body shape and in this case particularly head features might be affected by natural selection. In contrast, neutral genetic markers like microsatellites are considered to evolve independently from the highly complex mechanisms of natural selection so that differences in these loci can accumulate over time. Other evolutionary forces like mutation and genetic drift are more likely to be responsible for the genetic divergence among populations causing dissimilar pattern in genetic and morphological differentiation (Beebee \& Rowe, 2004; Halliburton, 2004). In wild populations, $P_{\mathrm{ST}}$ (Raeymaekers et al., 2007) represents an equivalent to $Q_{\mathrm{ST}}$ (Spitze, 1993) quantifying the proportion of among-population phenotypic variance. Comparing neutral genetic population differentiation $\left(F_{\mathrm{ST}}\right)$ to phenotypic differentiation $\left(P_{\mathrm{ST}}\right)$ could help separate effects of natural selection from effects of genetic drift contributing to the process of population differentiation in $A$. compressiceps but a sensible analysis of $F_{\mathrm{ST}} / P_{\mathrm{ST}}$ among wild populations would require more than the number of populations sampled for this study.

Clearly, further studies are needed to gain a better understanding of the processes driving or affecting speciation in the genus Altolamprologus. As described in Egger et al. (2007), nuclear and mitochondrial analyses may reveal different processes contributing to the formation of species. Additional nuclear genetic marker systems like microsatellites or
AFLPs comparing sympatric and allopatric A. compressiceps and $A$. calvus over the entire distribution range should be the next step to shed further light on the evolutionary relationships among species and populations.

Acknowledgements For help during sampling, we thank the team of the Mpulungu Station of the Department of Fisheries, Ministry of Agriculture, and Cooperatives, Republic of Zambia. CS was supported by the Austrian Science Foundation (grants I-48 and P20994). We also thank Michaela Kerschbaumer for her help with geometric morphometrics, Jaap van Schaik for his help with microsatellite data, Kristina Sefc and Stephan Koblmüller, as well as two anonymous referees, for valuable comments on the manuscript.

Open Access This article is distributed under the terms of the Creative Commons Attribution Noncommercial License which permits any noncommercial use, distribution, and reproduction in any medium, provided the original author(s) and source are credited.

\section{References}

Adams, D. C., F. J. Rohlf \& D. E. Slice, 2004. Geometric morphometrics: ten years of progress following the 'revolution'. Italian Journal of Zoology 71: 5-16.

Albertson, R. C. \& T. D. Kocher, 2001. Assessing morphological differences in an adaptive trait: a landmark-based morphometric approach. Journal of Experimental Zoology 289: 385-403.

Albertson, R. C., J. T. Streelman \& T. D. Kocher, 2003. Directional selection has shaped the oral jaws of Lake Malawi cichlid fishes. Proceedings of the National Academy of Sciences of the USA 100(9): 5252-5257.

Beebee, T. J. C. \& G. Rowe, 2004. An Introduction to Molecular Ecology. Oxford University Press Inc, New York.

Beerli, F. \& J. Felsenstein, 1999. Maximum-likelihood estimation of migration rates and effective population numbers in two populations using a coalescent approach. Genetics 152: 763-773.

Beerli, F. \& J. Felsenstein, 2001. Maximum-likelihood estimation of a migration matrix and effective population sizes in $\mathrm{n}$ subpopulations by using a coalescent approach. Proceedings of the National Academy of Sciences of the USA 98(8): 4563-4568.

Belkhir, K., P. Borsa, L. Chikhi, N. Raufaste \& F. Bonhomme, 1996-2004. GENETIX 4.05, logiciel sous Windows TM pour la génétique des populations. Laboratoire Génome, Populations, Interactions, CNRS UMR 5000, Université de Montpellier II, Montpellier (France) [available on internet at http://www.genetix.univ-montp2.fr/genetix/genetix. htm].

Boulenger, G. A., 1898. Catalogue of the Fresh-Water Fishes of Africa in the British Museum (Natural History), 3rd ed. British Museum, London. 
Brichard, P., 1999. Atlas der Tanganyikasee Cichliden. 2 Bände. Bede-Verlag, Ruhmannsfelden (2).

Bruford, M. W., O. Hanotte, J. F. Y. Brookfield \& T. Burke, 1993. Multilocus and single-locus DNA fingerprinting. Molecular genetic analysis of populations, Oxford University Press, New York: 287-336.

Carleton, K. L., J. T. Streelman, B.-Y. Lee, N. Garnhart, M. Kidd \& T. D. Kocher, 2002. Rapid isolation of CA microsatellites from the tilapia genome. Animal Genetics 33: $140-144$.

Cohen, A. S., M. J. Soreghan \& C. A. Scholz, 1993. Estimating the age of formation of lakes: an example from Lake Tanganyika, East-African rift system. Geology 21: 511-514.

Cohen, A. S., K. E. Lezzar, J.-J. Tiercelin \& M. Soreghan, 1997. New palaeogeographic and lake-level reconstructions of Lake Tanganyika: implications for tectonic, climatic and biological evolution in a rift lake. Basin Research 9: 107-132.

Colombe, J. \& R. Allgayer, 1985. Description de Variabilichromis, Neolamprologus, et Paleolamprologus genres nouveaux du Lac Tanganika, avec redescription des genres Lamprologus Schilthuis, 1891 et Lepidiolamprologus Pellegrin, 1904 (Pisces: Teleostei: Cichlidae). Revue Francaise des Cichlidophiles 49(9-16): 21-28.

Cornuet, J. M. \& G. Luikard, 1996. Description of power analysis of two tests for detecting recent bottlenecks from allele frequency data. Genetics 144: 2001-2014.

Crispo, E., C. Hagen, T. Glenn, G. Geneau \& L. J. Chapman, 2007. Isolation and characterization of tetranucleotide microsatellite markers in a mouth-brooding haplochromine cichlid fish (Pseudocrenilabrus multicolor victoriae) from Uganda. Molecular Ecology Notes 7: 1293-1295.

Day, J. J., S. Santini \& J. Garcia-Moreno, 2007. Phylogenetic relationships of the Lake Tanganyika cichlid tribe Lamprologini: the story from mitochondrial DNA. Molecular Phylogenetics and Evolution 45: 629-642.

De Vos, L. \& L. Seegers, 1998. Seven new Orthochromis species (Teleostei: Cichlidae) from the Malagarasi, Luiche and Rugufu basins (Lake Tanganyika drainage), with notes on their reproductive biology. Ichthyological Exploration of Freshwaters 9: 371-420.

Duftner, N., K. M. Sefc, S. Koblmüller, B. Nevado, E. Verheyen, H. Phiris \& C. Sturmbauer, 2006. Distinct population structure in a phenotypically homogenous rockdwelling cichlid fish from Lake Tanganyika. Molecular Ecology 15: 2381-2395.

Egger, B., S. Koblmüller, C. Sturmbauer \& K. M. Sefc, 2007. Nuclear and mitochondrial data reveal different evolutionary processes in the Lake Tanganyika cichlid genus Tropheus. BMC Evolutionary Biology 7: 137.

Endler, J. A., 1983. Natural and sexual selection on color patterns in poeciliid fishes. Environmental Biology of Fishes 9: 173-190.

Ernst, I., 2008. Evolution und Biogeographie der Gattung Altolamprologus im Tanganjikasee. Diplomarbeit. Institut für Zoologie, Karl-Franzens Universität Graz, Graz.

Excoffier, L., G. Laval \& S. Schneider, 2005. Arlequin ver. 3.0: an integrated software package for population genetics data analysis. Evolutionary Bioinformatics Online 1: 47-50.
Fryer, G. \& T. D. Iles, 1972. The Cichlid Fishes of the Great Lakes of Africa: Their Biology and Evolution. Oliver and Boyd, Edinburgh.

Greenwood, P. H., 1984. African cichlids and evolutionary theories. In Echelle, A. A. \& I. Kornfield (eds), Evolution of Fish Species Flocks. University of Maine at Orono Press, Orono: 141-154.

Halliburton, R., 2004. Introduction to Population Genetics, 1st ed. Pearson, Upper Saddle River.

Herler, J., L. Lipej \& T. Makovec, 2007. A simple technique for digital imaging of live and preserved fish specimens. Cybium 31(1): 39-44.

Hoffman, E. A., F. W. Schueler, A. G. Jones \& M. S. Blouin, 2006. An analysis of selection on a color polymorphism in the northern leopard frog. Molecular Ecology 15: 2627-2641.

Hubisz, M. J., D. Falush, M. Stephens \& J. K. Pritchard, 2009. Inferring weak population structure with the assistance of sample group information. Molecular Ecology Ressources 9: $1322-1332$.

Koblmüller, S., N. Duftner, K. M. Sefc, M. Aibara, M. Stipacek, M. Blanc, B. Egger \& C. Sturmbauer, 2007. Reticulate phylogeny of gastropod-breeding cichlids from Lake Tanganyika - the result of repeated introgressive hybridization. BMC Evolutionary Biology 7: 7.

Koblmüller, S., N. Duftner, K. M. Sefc, U. Aigner, M. Rogetzer \& C. Sturmbauer, 2009. Phylogeographic structure and gene flow in the scale-eating cichlid Perissodus microlepis (Teleostei, Perciformes, Cichlidae) in southern Lake Tanganyika. Zoologica Scripta 38: 257-268.

Konings, A., 1998. Tanganyika Cichlids in their Natural Habitat. Cichlid Press, El Paso

Kornfield, I. \& P. F. Smith, 2000. African cichlid fishes: model systems for evolutionary biology. Annual Review of Ecology and Systematics 31: 163-196.

Lezzar, K. E., J.-J. Tiercelin, M. De Batist, A. S. Cohen, T. Bandora, P. Van Rensbergen, C. Le Turdu, W. Mifundu \& J. Klerkx, 1996. New seismic stratigraphy and Late Tertiary history of the North Tanganyika basin, East Africa rift system, deduced from multichannel and high-piston core evidence. Basin Research 8: 1-28.

Maderbacher, M., C. Bauer, J. Herler, L. Postl, L. Makasa \& C. Sturmbauer, 2008. Assessment of traditional versus geometric morphometrics for discriminating populations of the Tropheus moorii species complex (Teleostei: Cichlidae), a Lake Tanganyika model for allopatric speciation. Journal of Zoological Systematic and Evolutionary Research 46(2): 153-161.

Martien, K. K., G. H. Givens \& E. Archer, 2007. A note on the ability of STRUCTURE to correctly infer the number of populations for Bering-Chukchi-Beaufort Seas bowhead whales. Paper SC/J07/AWMP5 presented to the International Whaling Commission intersessional workshop on the bowhead implementation review, January, 2007.

McGlue, M. M., K. E. Lezzar, A. S. Cohen, J. M. Russell, J.-J. Tiercelin, A. A. Felton, E. Mbede \& H. H. Nkotagu, 2008. Seismic records of late Pleistocene aridity in Lake Tanganyika, tropical East Africa. Journal of Paleolimnology 40: 635-653.

Poll, M., 1956. Poissons Cichlidae. In: Exploration Hydrobiologique du Lac Tanganika (1946/47). Résultats 
scientifiques 3 (5B):1-619. Institut Royal des Sciences Naturelles, Bruxelles.

Poll, M., 1986. Classification des cichlidae du lac Tanganika: tribus, genres et espèces. Académie Royal Belgian Memoires Classe Scientifique Collection tome XLV fascicule 2: 1-163.

Postl, L., J. Herler, C. Bauer, M. Maderbacher, L. Makasa \& C. Sturmbauer, 2008. Geometric morphometrics applied to viscerocranial bones in three populations of the Lake Tanganyika cichlid fish Tropheus moorii. Journal of Zoological Systematic and Evolutionary Research 46(3): 240-248.

Pritchard, J. K., M. Stephens \& P. Donnelly, 2000. Inference of population structure using multilocus genotype data. Genetics 155: 945-959.

Raeymaekers, J. A. M., J. K. J. van Houdt, M. H. D. Larmuseau, S. Geldorf \& F. A. M. Volckaert, 2007. Divergent selection as revealed by PST and QTL-based FST in three-spined stickleback (Gasterosteus aculeatus) populations along a coastal-inland gradient. Molecular Ecology 16: 891-905.

Rohlf, F. J., 2003. Tps Software Series. Department of Ecology and Evolution, State University of New York (SUNY), Stony Brook.

Schelly, R., W. Salzburger, S. Koblmüller, N. Duftner \& C. Sturmbauer, 2006. Phylogenetic relationships of the lamprologine cichlid genus Lepidiolamprologus (Teleostei: Perciformes) based on mitochondrial and nuclear sequences, suggesting introgressive hybridization. Molecular Phylogenetics and Evolution 38: 426-438.

Schupke, P., 2003. Cichlids of Lake Tanganyika, part 1: the species of the genus Tropheus. Aqualog, Rodgau: 190.

Seehausen, O. \& J. J. M. van Alphen, 1999. Can sympatric speciation by disruptive sexual selection explain rapid evolution of cichlid diversity in Lake Victoria? Ecology Letters 2: 262-271.

Sefc, K. M., S. Baric, W. Salzburger \& C. Sturmbauer, 2007. Species-specific population structure in rock-specialized sympatric cichlid species in Lake Tanganyika, East Africa. Journal of Molecular Evolution 64: 33-49.

Sheets, H. D., 2003. IMP-Integrated Morphometrics Package. Department of Physics, Canisius College, Buffalo [available on internet at http://www3.canisius.edu/ sheets/ morphsoft.html].

Slatkin, M., 1993. Isolation-by-distance in equilibrium and non-equilibrium populations. Evolution 47(1): 264-279.

Slatkin, M., 1995. A measure of population subdivision based on microsatellite allele frequencies. Genetics 139: 457-462.
Spitze, K., 1993. Population structure in Daphnia obtusa: quantitative genetic and allozymic variation. Genetics 135: 367-374.

Stiassny, M. L. J., 1991. Phylogenetic interrelationships of the family Cichlidae: an overview. In: Keenleyside, M. H. A. (ed.) Behaviour, ecology and evolution. Chapman and Hall, London.

Sturmbauer, C., 1998. Explosive speciation in cichlid fishes of the African Great Lakes: a dynamic model of adaptive radiation. Journal of Fish Biology 53(Suppl A): 18-36.

Sturmbauer, C. \& A. Meyer, 1992. Genetic divergence, speciation and morphological stasis in a lineage of African cichlid fishes. Nature 358: 578-581.

Sturmbauer, C., E. Verheyen \& A. Meyer, 1994. Mitochondrial phylogeny of the Lamprologini, the major substrate spawning lineage of cichlid fishes from Lake Tanganyika in Eastern Africa. Molecular Biology and Evolution 11(4): 691-703.

Sturmbauer, C., S. Baric, W. Salzburger, L. Rüber \& E. Verheyen, 2001. Lake level fluctuations synchronize genetic divergences of cichlid fishes in African lakes. Molecular Biology and Evolution 18(2): 144-154.

Van Oosterhout, C., W. F. Hutchinson, D. P. M. Wills \& P. Shipley, 2004. MICRO-CHECKER: software for identifying and correcting genotyping errors in microsatellite data. Molecular Ecology Notes 4: 535-538.

van Oppen, M. J. H., C. Rico, J. C. Deutsch, G. F. Turner \& G. M. Hewitt, 1997. Isolation and characterization of microsatellite loci in the cichlid fish Pseudotropheus zebra. Molecular Ecology 6: 387-388.

Verheyen, E., L. Ruber, J. Snoeks \& A. Meyer, 1996. Mitochondrial phylogeography of rock-dwelling cichlid fishes reveals evolutionary influence of historical lake level fluctuations of Lake Tanganyika, Africa. Philosophical Transactions of the Royal Society of London B Biological Sciences 351(1341): 797-805.

Weir, B. S. \& C. C. Cockerham, 1984. Estimating F-Statistics for the analysis of population structure. Evolution 38(6): 1358-1370.

Wright, S., 1931. Evolution in Mendelian populations. Genetics 16: 97-259.

Yuma, M., 1994. Food habits and foraging behaviour of benthivorous cichlid fishes in Lake Tanganyika. Environmental Biology of Fishes 39: 173-182.

Zardoya, R., D. M. Vollmer, C. Craddock, J. T. Streelman, S. Karl \& A. Meyer, 1996. Evolutionary conservation of microsatellite flanking regions and their use in resolving the phylogeny of cichlid fishes (Pisces: Perciformes). Proceedings of the Royal Society of London 263: 1589-1598. 